\title{
A evolução do estresse e a fase de quase-exaustão como fator desencadeador da depressão
}

Evolution of stress and the phase of almostexhaustion as a depressing fator

La evolución del estrés y la fase de cuales-exaustión como factor desencador de la depresión

Revista Dissertar No30 V.1 ANO XIV

DOI: $10.24119 / 16760867$ ed114236

Data de submissão: 10-08-2018

Data de aceite: $30-10-2018$

por Adelmo Senra Gomes ${ }^{1}$ Geovanna Vicente ${ }^{2}$ da Silva e Rafaela Rocha Aranzate $^{3}$

\section{Resumo}

O presente artigo tem como objetivo descrever o conceito do estresse, explicitando suas fases, as descobertas que contribuíram para a sua consolidação no campo científico, e como se deu o surgimento da fase Quase-Exaustão, verificando como a homeostase do indivíduo é afetada por eventos estressores e como isso contribui para a depressão. Trata-se de uma pesquisa de natureza básica e objetivo descritivo, com metodologia baseada em levantamento e análise segundo a abordagem qualitativa. Verificaram-se, no decorrer das fases do estresse, lacunas que propiciam o desenvolvimento da depressão e suas variedades patológicas. Elucida como as patologias da contemporaneidade afetam o indivíduo, no seu aspecto social e deterioram sua capacidade de equilíbrio. Observou-se que o estresse afeta o organismo físico modificando sua estrutura, causando desequilíbrio no funcionamento cerebral e alterações hormonais que proporcionam o aparecimento de doenças psicossomáticas e psicológicas.

Palavras-chaves: Depressão. Estresse. Qualidade de vida.

1 Adelmo Senra Gomes: Possui graduação em Psicologia pela Universidade Gama Filho e pós-graduação em Filosofia e Psicologia Jurídica pela UERJ. Foi professor auxiliar da Universidade do Grande Rio - Prof. José de Souza Herdy e da Universidade Estácio de Sá. Tem experiência na área clínica e jurídica da Psicologia Leciona as cadeiras de Psicopatologia, Psicopatologia Foresene e Filosofia no curso de Psicologia e de Psicologia Aplicada ao Direito no curso de Direito. E-mail: adelmopsic61@gmail.com

2 Geovanna Vicente da Silva: Graduada em psicologia. E-mail: geovanna. vicente@hotmail.com

3 Rafaela Rocha Aranzate: Graduada em psicologia. E-mail: rafaela. aranzate@gmail.com 


\section{Abstract}

This article aims to describe the concept of stress, explaining its phases, the findings that contributed to the consolidation of stress in the scientific field and how the emergence of the Exhaustion phase occurred, verifying how the individual's homeostasis is affected by events stressors and how this contributes to depression. It is a research of a basic nature and a descriptive objective, with methodology of survey and analysis according to a qualitative approach. During the phases of stress, there were gaps that favored the development of depression and its pathological varieties. They elucidate how the pathologies of contemporaneity affect the individual in his social aspect and deteriorate his ability to balance. It has been observed that stress affects the physical organism by modifying its structure, causing an imbalance in brain functioning and hormonal changes that lead to the onset of psychosomatic and psychological illnesses.

Keywords: Depression. Stress. Quality of life

\section{Resumen}

This article aims to describe the concept of stress, explaining its phases, the findings that contributed to the consolidation of stress in the scientific field and how the emergence of the Exhaustion phase occurred, verifying how the individual's homeostasis is affected by events stressors and how this contributes to depression. It is a research of a basic nature and a descriptive objective, with methodology of survey and analysis according to a qualitative approach. During the phases of stress, there were gaps that favored the development of depression and its pathological varieties. They elucidate how the pathologies of contemporaneity affect the individual in his social aspect and deteriorate his ability to balance. It has been observed that stress affects the physical organism by modifying its structure, causing an imbalance in brain functioning and hormonal changes that lead to the onset of psychosomatic and psychological illnesses.

Palabras chaves: Depression. Stress. Quality of life

\section{Introdução}

E crescente a preocupação com assuntos referentes à qualidade de vida, sendo esse um conceito muito abrangente que envolve não apenas a saúde física, como também a mental, em diferentes aspectos de vida do sujeito. Qualidade de vida engloba as relações sociais e relações com o meio ambiente, além dos aspectos físicos, psicológicos e emocionais, ou seja, diz respeito ao bem estar nos mais variados parâmetros que afetam a vida do ser humano, tanto no âmbito básico quanto no suplementar.

O estresse é um conceito bastante conhecido. Hans Selye, considerado o "pai da estressologia", por ter sido o pioneiro no 
assunto, propôs que o estresse surge quando o organismo passa por alguma situação que exigiria sua adaptação. Quando essa adaptação não ocorre ou torna-se muito difícil, ocorreria uma reação no organismo, denominada por Selye, de Síndrome da Adaptação Geral. Em suas quatro décadas de pesquisas (1936-1976), Selye ampliou o conceito proposto por Walter Cannon referente à homeostase, que corresponderia à capacidade de o organismo autorregular seus sistemas diante de mudanças em seu equilíbrio interno. A tendência do organismo é buscar reestabelecer o estado anterior de equilíbrio, acionando, assim, mecanismos fisiológicos. Porém, é evidente que há limites para o processo de homeostase involuntária e automática, sendo de extrema importância que o organismo busque suprir, voluntariamente, o que não puder ser equilibrado através dessa autorregulação interna. Atualmente, os estudos relacionados ao estresse não procuram estabelecer relações apenas com a mente e o corpo, mas também sobre suas interferências nas relações sociais e individuais.

Outro fator cada vez mais frequente é a depressão, sendo uma das alterações afetivas mais estudadas na atualidade: é denominada como a doença da sociedade moderna, "o mal do século". (DANTAS; MOURA, 2011). A evolução histórica demonstra grandes avanços e conquistas de forma geral, como, por exemplo, na perspectiva tecnológica, que podem, por um lado, trazer benefícios; mas, por outro, podem estar, gerando comprometimentos à saúde de forma silenciosa. As pessoas se cobram cada vez mais, por isso, as pressões do cotidiano podem gerar sofrimento psíquico para quem está fragilizado. Como consequência, esse esgotamento pode ocasionar alguma patologia, como a depressão, alterando a percepção de si e transformando até mesmo os problemas pequenos em grandes catástrofes. (ESTEVES; GALVAN, 2006).

Esse levantamento bibliográfico busca responder ao questionamento sobre qual seria a relação possível entre o estresse e a depressão. Como patologias da modernidade, estresse e depressão representam uma grande demanda nos consultórios de psicólogos. Pesquisas acerca dessa relação viabilizam como entender a dinâmica do estresse e da depressão no funcionamento psíquico, proporcionando novos estudos para o mundo científico e para a sociedade. Portanto, a proposta desta pesquisa, que é de natureza básica e objetivo descritivo, com metodologia baseada em levantamento e análise segundo a abordagem qualitativa, é agregar a propagação da visão de aspectos psicológicos, neurobiológicos e sociais a respeito dos assuntos tratados, utilizando-se também de entrevistas com profissionais para enriquecer as questões pertinentes ao tema.

Assim, o objetivo desta pesquisa é descrever o estresse, suas fases e os conceitos acerca da depressão, investigando as lacunas de seu desenvolvimento que favoreçam o surgimento da depressão. 
Buscou-se delinear a evolução conceitual do estresse ao abranger aspectos teóricos; apontar a depressão como uma complexidade na vida moderna; problematizar a relação que constituímos com nossa vida na atualidade (relacionando ambas as variáveis), buscando gerar debates e colaboração para o meio científico.

\section{Estresse: conceitos e perspectivas}

Qualidade de vida, abordada por muitos autores, é tão complexa que não há consenso conceitual. Diferentes áreas abordam de formas distintas, não obstante, na tentativa de contribuir para o esclarecimento. É evidente que esta preocupação em torno da conceituação levanos a classificá-la não apenas como saúde, ou ausência de doença, e, sim, de modo mais abrangente, envolvendo fatores relacionados às circunstâncias do cotidiano. Desse modo, atualmente, os conceitos mais aceitos englobam aspectos gerais, como, por exemplo, o da Organização Mundial de Saúde (OMS), que preconiza que qualidade de vida é:

A percepção do indivíduo sobre seu posicionamento na vida dentro do contexto cultural e o sistema de valores em que vive e com respeito aos seus objetivos, expectativas, normas e preocupações. É um conceito extenso e complexo que engloba a saúde física, o estado psicológico, o nível de independência, as relações sociais, as crenças pessoais e a relação com as características principais do ambiente. (Conferência OMS, 1998, p. 28, original em espanhol).

Dentre as principais abordagens sobre qualidade de vida, existe a psicológica, que a divide em seis dimensões de análises, apresentadas por Day e Jankey (2006 apud PEREIRA, 2012). A primeira diz respeito aos objetivos e realizações, ou seja, o que se tem atualmente e o que se quer ter; a segunda é a análise do que as pessoas de fato acreditam ser o ideal verídico de vida; a terceira dimensão é a conexão inferida entre a condição atual e o que se objetiva no futuro, o que se deseja tornar; a quarta refere-se à comparação entre como está a qualidade de vida atual e durante a vida, qual foi a melhor já estabelecida; a quinta situação é o que se tem, tanto individual quanto em um grupo modelo; e a sexta dimensão é clarificar como pode ser boa a adaptação de cada um em seu ambiente.

Frente a conceituação de qualidade de vida compreendida como algo amplo, e as dimensões psicológicas, podemos nos remeter às questões que atingem o ser e proporcionam um declínio nessa qualidade. Uma dessas questões, o estresse, é uma reação que interfere na qualidade dos aspectos psicológicos, mentais, físicos e hormonais, que pode surgir diante das situações consideradas desafiadoras pela pessoa. (LIPP; MALAGRIS, 2001 apud OLIVEIRA, 2006). A outra questão, a depressão, promove alterações que interferem física e 
psicologicamente. (HALGIN; WHITBOURNE, 2015).

Existem eventos de vida que produzem estresse e interferem na saúde mental, sendo fatores de risco para transtornos mentais na população, eventos esses como: altas taxas de desemprego, violência, criminalidade, desigualdades sociais e como más condições de saúde, renda e moradia, e crescimento acelerado da sociedade urbana. (CHOR, 2003).

Nesse primeiro momento, nosso foco será o estresse, sua menção, conceituação, e perspectivas, para então, em um segundo momento, focarmos na depressão e sua relação com o estresse.

Quando se estuda a adaptação dos seres humanos diante de adversidades ou diante de mudanças, a palavra estresse está relacionada. Sua primeira menção, no século XIV, foi, justamente, por se referir às situações adversas, e, de lá até o século XIX, o conceito foi evoluindo até chegar à questão da ação e reação, ou seja, a exposição a algo e a habilidade de suportá-lo. Estudos na área da fisiologia, por Claude Bernard, levaram à conclusão de que o organismo deve estar estável interiormente para se manter e sobreviver. (GONZÁLEZ, 2001 apud FARO; PEREIRA, 2013). Nesse ponto, ficou claro que alterações ambientais externas poderiam desestabilizar e alterar a fisiologia pela falta de equilíbrio. Baseado nisso, Walter Cannon surge com o conceito de homeostase e como a desestabilização a afeta. Com seus estudos, Cannon propôs que o organismo regula seu funcionamento fisiológico através da manutenção e defesa, buscando o equilíbrio e tornandose adaptativo diante das várias modificações no espaço externo, que também influenciam internamente. (CANNON, 1935 apud FARO; PEREIRA, 2013).

Hans Selye, em 1936, publicou o primeiro trabalho relacionado ao estresse em que associou a homeostase proposta por Cannon a estímulos danosos, nos quais ela seria alterada por meio de um aglomerado de respostas do sistema endócrino, quando se deparam com estímulos adversos. Sua referência biológica tinha o objetivo de se aprofundar nessas respostas fisiológicas e de perceber a fronteira tênue entre o âmbito da aptidão para sobreviver e o declínio da saúde diante das constantes adversidades da vida. (VINER, 1999 apud FARO; PEREIRA, 2013).

Desde a sua primeira menção, gradativamente, o estresse tornou-se objeto de estudo em diferentes áreas, nas quais cada uma delas preza por ter sua particularidade de acordo com a perspectiva do campo teórico. As ciências biológicas levarão em conta a parte fisiológica, como o corpo reage diante de estímulos adversos, enquanto que as ciências sociais basear-se-ão na interação e contexto sóciohistórico, ou seja, adaptação social. A psicologia associa a percepção das ciências biológicas e sociais, porém, seu enfoque está pautado no entendimento da relação do indivíduo com o meio, considerando tudo que o rodeia. Apesar de cada área de estudo ter um enfoque particular, 
todas consideram, como base de pensamento, que alguns estímulos são capazes de provocar desequilíbrios. (FARO; PEREIRA, 2013).

Três perspectivas teóricas explicam a evolução conceitual do estresse, sendo elas: perspectiva baseada na resposta, que se refere à parte biológica; perspectiva baseada no estímulo, que se refere aos eventos sociais e psicossociais que geram respostas neurofisiológicas; e perspectiva cognitivista, que se refere à relação indivíduo-meio capaz de gerar estresse. Aprofundando em cada uma das três perspectivas, percebemos que a primeira, baseada na resposta, surgiu demonstrando que o organismo apresenta uma padronização de resposta, quando a homeostase é alterada, procurando reestabelecer-se através do desencadeamento de reações gerais neurofisiológicas.

Selye, precursor da teoria e referência nessa perspectiva, considera o estresse como uma resposta fisiológica inespecífica diante do que desorganize a condição de homeostase (SELYE, 1954, 1993 apud FARO; PEREIRA, 2013), e ainda apontou quatro aspectos sob a ótica do estresse. O primeiro deles, inespecificidade da resposta, diz respeito à Síndrome da Adaptação Geral (SAG), um conjunto habitual de reações neurofisiológicas para o reestabelecimento da homeostase, que prosseguem em uma sequência de três etapas: Alarme, etapa inicial, que é caracterizada pela condição luta - fuga; Resistência, habilidade de o organismo resistir à pressão do agente estressor durante um período; o último, Exaustão, estabelece-se quando as funções adaptativas da resistência se esgotam devido ao desgaste, ou seja, o contato com o agente estressor pode ser breve ou o organismo pode apresentar recursos para lidar com a situação, o que fará com que a fase de Alarme se interrompa e dê início ao processo de homeostase. No entanto, caso o estressor seja mais persistente, ocorre a fase da Resistência, que irá consumir energia adaptativa para suportar o estresse apenas até o limite do indivíduo, considerando o tempo de exposição e intensidade, e, então, ultrapassada a tolerância limite, o organismo desgasta-se cada vez mais, fragiliza-se, e tornase vulnerável à doenças, devido ao comprometimento das funções biológicas, evidenciando a fase de Exaustão.

A energia adaptativa necessita de diminuição ou inexistência de desgaste para se recompor, com isso, os sistemas de defesa do organismo possuem propensão a declinarem diante do excesso de desgaste, gerando danos em órgãos e tecidos. Diante das primeiras alterações biológicas após a Exaustão, Selye demonstrou que ocorre hiperatividade do córtex suprarrenal, que ativa hormônios, como o cortisol, e atrofia o timo dos gânglios linfáticos, que reduz a imunidade e libera ácidos digestivos, que contribuem para a formação de úlceras. Com isso, patologias que tenham relação com alterações hormonais, infecções e gastrites são comuns. (SELYE, 1936, 1954 apud FARO; PEREIRA, 2013).

O modelo trifásico proposto por Hans Selye foi expandido 
por Lipp (2001) em pesquisas desenvolvidas durante 15 anos, que identificou outra fase, denominada fase de Quase-Exaustão, localizando-se entre a fase de Resistência e a fase de Exaustão; assim, a autora propôs um modelo quadrifásico. Essa fase se configura pelo início do adoecimento e sinais de deterioração de órgãos de maior vulnerabilidade genética ou adquirida, indicando que a fase de Resistência não está conseguindo suportar as pressões dos agentes estressores e, caso os agentes estressores permaneçam, estabelece-se a fase final, a Exaustão, a partir da qual podem surgir doenças graves. Durante a Quase-Exaustão, a pessoa consegue, de certa forma, agir em sociedade; porém, na Exaustão, o funcionamento já não é mais adequado. A depressão, por exemplo, pode surgir na fase de QuaseExaustão e evoluir para a fase de Exaustão. (LIPP, 2001).

Uma crítica à perspectiva baseada na resposta, é que ela se torna limitada à espera da resposta biológica, para, então, definir a sua intensidade e sua origem. (URSIN; ERICKSEN, 2004 apud FARO; PEREIRA, 2013). O próprio Selye percebeu que seria útil expandir seu conceito para além do biológico, indagar sobre as peculiaridades das respostas frente ao estresse e estudar, a fundo, as propriedades dos estressores. (SELYE, 1954, 1993; VINER, 1999 apud FARO; PEREIRA, 2013).

Frente a essa crítica, surgiu outra categoria para explicar o estresse, a perspectiva baseada no estímulo, que considera os eventos externos e seus potenciais para produzir respostas e reações pelo contato com estressores. Desse modo, percebe-se que o foco dessa perspectiva é o fato em si e não apenas a parte biológica, como propunha a perspectiva anterior, ou seja, os estímulos estressores que atingem os indivíduos ocasionam um conjunto de respostas no organismo, que atingem a capacidade adaptativa.

O grande conceito dessa perspectiva é denominado de Eventos Vitais Estressores (EVE), que são acontecimentos alarmantes que irão exigir certa parcela de empenho adaptativo, definindo o quanto de energia será gasta para manter a regulação de ajustamento, ou seja, um evento estressante pode consumir energia em maior ou menor grau, podendo ocorrer algum dia na vida de qualquer um. Uma pesquisa realizada por Holmes e Rahe com 5000 pessoas que passaram pelas mais variadas situações, das mais graves às menos graves, serviu para constatar que antes de uma patologia, são vivenciadas experiências semelhantes. A conclusão entre o grau de intensidade de um evento estressante, foi de que um evento de maior intensidade é capaz de sozinho levar à patologias, enquanto os eventos de potencial menor se acumulam deteriorando a adaptação do indivíduo, que acabam, depois de um tempo, tendo o mesmo peso de um evento grave. A partir de testes, desenvolveram a Escala de Reajustamento Social (Social Readjustment Rating Escale - SRRE), onde listaram 43 situações mais comuns capazes de provocar estresse, com a proposta de que, ao 
se verificar as experiências de maior nível estressor para uma pessoa, seria provável estabelecer um diagnóstico de estresse e o quanto sua saúde estaria abalada por ser exposta a tal evento. Para cada evento da SRRE foi concedido um valor nomeado de Unidade de Mudança na Vida (Life Change Unit - LCU), que se refere ao grau de empenho para adaptar-se, e, então, foi calculado o quão provável seria o adoecimento por conta do EVE, sendo então entre 150 a 199 LCU 37\%; de 200 à 300 LCU 51\%; e, acima de 300 LCU, 79\% de chance de adoecimento por estresse. Portanto, nesses estudos sobre o estresse, o importante era avaliar as mudanças que ocorriam por meio de demandas estressoras, que então ocasionariam em alterações biológicas. (HOLMES; RAHE 1967 apud FARO; PEREIRA, 2013).

A perspectiva baseada no estímulo sofreu críticas por não levar em conta emoções, significados, desejos e diferenças individuais, assim como a interpretação individual que fará com que o mesmo evento possa ser distinto para cada pessoa, devido à subjetividade. Com isso, no final da década de 1980, estudos sobre EVE foram diminuindo em consequência da necessidade de aprimorar-se em termos de concepção da variedade de respostas ao estresse, visto que ao se criar modelos e generalizações pouco se descobre a respeito das pequenas variações. Além disso, essa perspectiva não considerou os mecanismos adaptativos, que podem fazer com que a resposta a um evento estressor possa ser minimizada ou maximizada, tornando-se dificultoso estabelecer a diferenciação de quando realmente o estresse ocorreu e quando o organismo está apenas reagindo para se manter em seu estado habitual. Frente a isso, surgiu a perspectiva cognitiva, que consideraria as diferenças individuais e a subjetividade. (FARO; PEREIRA, 2013).

A perspectiva cognitiva leva em conta o que antecede, os vários processos e o resultado, estabelecendo a relação entre estímulo, organismo e resposta (E-O-R); parte do princípio de que, quando um estressor (E) está além da capacidade adaptativa $(\mathrm{O})$, surgem respostas frente ao estresse. Nem todas as experiências são estressoras, como propunha a perspectiva baseada na resposta, nem todos os estressores produzirão estresse em todos os indivíduos, como propunha a perspectiva baseada no estímulo. Com isso, a cognição é responsável por indicar o porquê e a proporção com que a relação entre ambientes e pessoas é estressora. O estresse não se define em um único processo, já que o indivíduo busca novas formas de ajustamento através de mecanismos de adaptação, mudando a forma como percebe e como reage, buscando o término do estresse, passando pelos seguintes momentos: estressor $\rightarrow$ avaliação $\rightarrow$ enfrentamento $\rightarrow$ reação ao estresse $\rightarrow$ desfecho $\rightarrow$ reavaliação $\rightarrow$ estressor com nova conformação $\rightarrow$ enfrentamento $\rightarrow$ e assim por diante. (LAZARUS, 1993 apud FARO; PEREIRA, 2013).

Com isso, o nível de estresse se estabelece de acordo com o 
significado concedido pela pessoa em sua relação com o ambiente e, então, pesquisas procuraram estabelecer o porquê de alguns estressores afetarem tão rapidamente alguém e em outros não fazerem diferença. As diferenças individuas foram consideradas para explicar a propensão ao estresse de forma direta, pela fragilidade adquirida ou inata, ou indiretamente pela influência de terceiros durante o encadeamento estressor - avaliação - resposta. (FARO; PEREIRA, 2013).

A perspectiva cognitiva é portanto a que prevalece na psicologia, não desconsiderando, é claro, as contribuições que as outras abordagens trouxeram; porém, se torna mais completa por considerar a individualidade, estímulo, resposta, interação e percepção. (FARO; PEREIRA, 2013).

\section{Pesquisa sobre o estresse no brasil}

Em 2014, foi realizada uma pesquisa no Brasil, de modo online, em nível nacional, com a participação de 2.195 brasileiros, dos 18 aos 75 anos, sendo $25,65 \%$ do sexo masculino e $74,35 \%$ do sexo feminino, por um período de 45 dias, pelo Instituto de Psicologia e Controle do Estresse (IPCS), sob a direção da doutora Marilda Lipp, que é diretora do Instituto.

O IPCS busca gerar, aprofundar e difundir conhecimento acerca do estresse, por meio de pesquisas que visem contribuir para o bem estar do ser humano e fazer com que as pessoas possam lidar com o estresse de forma eficaz, melhorando, portanto, os vários aspectos profissionais, afetivos, sociais e referentes à saúde. Todas as informações sobre a pesquisa foram retiradas do site do Instituto.

Não existia uma pesquisa dessa natureza no Brasil, e a ideia de fazêla veio de uma pesquisa também online efetuada nos Estados Unidos em 2012, pela Associação Americana de Psicologia (APA), em 2.020 americanos, intitulada de Stress in America, para verificar o estresse nos americanos.

Os objetivos da pesquisa no Brasil verificaram como os brasileiros se auto percebem, se julgam saber lidar ou não com o estresse, se acham que o estresse aumentou ou não em relação com o passado, quais as principais fontes do estresse, como enfrentam e quais doenças podem estar relacionadas com o estresse.

No aspecto de autopercepção do nível do estresse, utilizando uma escala de 1 a 10 , sendo 1 o mínimo e 10 o máximo, 34,26\% declararam passarem pelo estresse nos níveis 8 , 9, e 10, ou seja, estresse no extremo, muito elevado; já na pesquisa americana, apenas $20 \%$ declararam o mesmo nível. O estresse máximo, ou seja, 10 pontos na escala 10, foi atribuído por $4,02 \%$ dos brasileiros que declaram vivenciarem.

No aspecto de responderem o quanto consideram normal o nível de estresse que estão vivenciando, e o que seria considerado bom para um adulto, 91,96\% dos participantes alegaram que o ideal seria 
o nível 5 a 6, em uma escala de 1 a 10; 33\% afirmaram passar por um nível acima do aceitável; e apenas 11,96\% estabeleceram que passam por um nível normal de estresse.

Comparando o estresse atual com o do passado, 37,79\% relataram que o nível está maior ou muito maior, $47,29 \%$ acham que o estresse diminuiu e 15,02\% acham que está o mesmo. Nos Estados Unidos, 35\% dos participantes acreditam que o estresse aumentou, ou seja, no Brasil o número de pessoas que também acham que o nível está mais elevado é maior.

No quesito saber lidar com o estresse, apenas 2,86\% dos participantes acreditam saber lidar de modo formidável, 61,21\% acreditam que lidam em parte, e 2,52\% não lidam de forma alguma. Com relação às doenças, $52,28 \%$ relataram que já tiveram ou tem diagnóstico de estresse, 55,60\% têm ou já tiveram ansiedade, 23,20\% têm ou já tiveram diagnóstico de depressão, 10,37\% têm ou já tiveram pânico, sendo todas essas patologias de origem psicológica. Já as doenças psicossomáticas, as que lideram são gastrite com $32,64 \%$ e asma e outras doenças respiratórias com 20,45\%.

No que mais faz surgir estresse, em primeiro lugar, com $18,56 \%$, estão as relações interpessoais; em segundo lugar, com 17,32\%, estão dificuldades financeiras; e, em terceiro lugar, sobrecarga no trabalho, com 16,58\%. Como as relações interpessoais ficaram em primeiro lugar, foi averiguado que tipo de relação causa maior nível de estresse, e se constatou que em primeiro lugar está o relacionamento familiar com $7,85 \%$, seguido de $7,01 \%$ de relacionamentos amorosos.

$\mathrm{Na}$ questão de como os brasileiros enfrentam o estresse, em primeiro lugar está que $75,74 \%$ dos entrevistados conversam com amigos e familiares para tentar diminuir o nível de estresse; 71,37\% tenta se auto analisar para eliminar a fonte do estresse; $63,97 \%$ procuram fazer exercícios; $62,45 \%$ fazem orações, irradiações mentais ou rezam; $59,56 \%$ leem revistas ou livros; $53,87 \%$ comem; $42,60 \%$ procuram um psicólogo; 38,53\% fazem compras; 37,25\% fazem massagem; 32,25\% vão ao salão de beleza; 25,69\% procuram um médico; $21,81 \%$ fazem uso de calmantes ou outros medicamentos; $16,52 \%$ utilizam bebida alcoólica; $16,23 \%$ procuram um profissional acupunturista; 15,83\% procuram um centro espírita; $10,39 \%$ procuram padre ou pastor; $9,75 \%$ fumam cigarros; 3,19\% fumam maconha; e 0,69\% utilizam cocaína ou outras drogas.

Analisando os dados obtidos, conclui-se que $34,26 \%$ das pessoas entrevistadas consideram o seu nível de estresse como muito elevado e 4,02\% chegando ao extremo. Os brasileiros tentam manter o nível de estresse entre 5 e 6 sendo o que consideram normal, utilizando-se de várias possibilidades como conversas com amigos, orações, compras, comidas, e muitos outros, sendo que $42,60 \%$ buscam ajuda profissional de um psicólogo. Mais de um terço dos entrevistados sentem que o nível de estresse aumentou com o passar do tempo e 2,52\% não 
conseguem lidar com isso. Relacionamentos são o topo dos estressores, seguidos de dificuldade financeira e trabalho. Mais da metade dos entrevistados tem ou tiveram diagnóstico de estresse e $23,20 \%$ têm ou tiveram depressão relacionada ao estresse como causa psicológica. (LIPP, 2014).

\section{Aspectos da depressão}

A depressão é considerada a patologia da modernidade, visto que, nos últimos anos, sua crescente demanda e diagnósticos em grande escala geram uma discussão acerca dessa doença, que vem aumentando em níveis alarmantes. Segundo a OMS, até 2020, a depressão será uma das doenças mais incapacitantes. (BEM ESTAR G1, 2017). No mundo, são 322 milhões de pessoas, cerca de $4,4 \%$ da população mundial que sofrem de depressão. O Brasil fica em primeiro no ranking, sendo considerado o país da América Latina com mais depressivos. (EXTRA, 2017).

Pelo viés psiquiátrico, a depressão é considerada como desequilíbrio entre funções químicas cerebrais, destacando a desarmonia dos neurotransmissores, serotonina e noradrenalina, com sintomas de tristeza profunda, apatia, desânimo, distúrbios alimentares com propensão a perda ou ao aumento do apetite. O DSM (Manual Diagnóstico e Estatístico de Transtornos Mentais) possui uma seção somente para classificar os transtornos depressivos, já que suas ramificações patológicas são diversas. A visão médica psiquiátrica limita o sujeito aos sintomas deixando de lado a subjetividade humana. Utiliza-se do meio científico e da visão biológica para explicar os problemas psicopatológicos que possam ser tratados com psicofármacos, que reflete no crescente consumo de antidepressivos e remédios psicotrópicos em transtornos mentais, consequentemente movimentando a indústria farmacêutica. (DANIEL; SOUZA, 2006).

A depressão é vivenciada em todos os campos da vida do sujeito, sendo assim seu novo jeito de viver; o estresse não fica atrás e também é responsável pelo afastamento de pessoas no trabalho. No que diz respeito à depressão, acreditamos que os estímulos divulgados pelos meios de comunicação, especialmente a internet e as redes sociais, estimulam um padrão de felicidade, como se para alcançar essa tal felicidade haja uma receita a ser seguida. Partindo dessa ideia, Dantas e Moura mencionam:

Nosso cenário capitalista e consumista parece moldar o que sentimos, o que vestimos e o que queremos com impressionante eficácia. Esses modelos prontos sobre o que devemos fazer para sermos felizes, o que devemos comer para termos beleza e saúde ou o que devemos buscar se quisermos sucesso e dinheiro parecem ser receitas vendidas diariamente nas bancas de jornal. As respostas sobre nossas vidas parecem estar tão claras e 
absurdamente dependentes apenas de um esforço pessoal para resolver qualquer problema. (DANTAS; MOURA, 2011, p.91).

Com base na ideia de Freud, não há como isolar a doença do seu contexto social, já que as necessidades individuais muitas vezes diferem das imposições dos vários aspectos culturais e sociais que se estabelecem em uma determinada época. (FREUD, 1931 apud AZEVEDO; MAGALHÃES, 2016).

As ramificações patológicas dos sintomas depressivos são retratadas em outros quadros clínicos como o transtorno depressivo maior que envolve sintomas depressivos agudos, mas com tempo limitado. Esse período é chamado de episódio depressivo maior. Critérios diagnósticos mediante os sintomas e tempo de duração que aquela pessoa se encontra em estado depressivo são estabelecidos para que o diagnóstico seja confirmado. $\mathrm{O}$ transtorno depressivo maior pode ser diagnosticado como uma comorbidade presente em outros transtornos de personalidade, ansiedade e esquizofrenia. Envolve transtornos esquizioafetivo, esquizofrenia, transtorno esquizofreniforme, e transtorno delirante. Logo, uma avaliação minuciosa precisa ser realizada para que os demais transtornos sejam descartados. A incidência de transtorno depressivo maior ao longo da vida é de 16,6\% nos Estados Unidos, na população adulta. A prevalência do transtorno depressivo em mulheres, é de $70 \%$ maior do que em homens. (DEMLER et.al, 2005 apud HALGIN; WHITBOURNE, 2015).

$O$ transtorno depressivo persistente, também chamado de distimia, é uma perturbação no humor de forma persistente e crônica que pode durar até 2 anos ( 1 ano para crianças e adolescentes) com um conjunto mais restrito de sintomas, incluindo alterações no sono, distúrbios alimentares, baixa energia ou fadiga, baixa autoestima, dificuldade na concentração, na tomada de decisões e com sentimentos de desesperança. Esse transtorno é caracterizado por sintomas mais brandos e de menor intensidade comparado com o transtorno depressivo maior, apesar disso os sintomas persistem pelo menos até dois meses. Além disso, podem desencadear outras doenças mentais como transtorno depressivo maior, transtorno de personalidade e transtorno por uso de substância. Por serem transtornos com episódios depressivos, a diferença entre o transtorno depressivo maior e a distimia é dada pelo grau de intensidade e pelo tempo de duração de cada episódio depressivo. A classificação para diferenciá-los é dada a partir de uma avaliação psiquiátrica apurada para saber se o sujeito se enquadra nos critérios diagnósticos de ambos transtornos. Apesar de apresentarem diferenças, o transtorno depressivo maior pode aparecer como comorbidade no quadro distímico:

A distimia de início precoce possui, ainda, maiores taxas de comorbidade com depressão maior e transtorno de ansiedade e 
maior propensão para história familiar de transtornos afetivos. Barzega et al. estudaram características clínicas da distimia em relação à idade de início, encontrando relação entre eventos estressantes (doença, separações) anteriores ao transtorno e distimia de início tardio, sugerindo uma ligação etiológica. Os autores encontraram, ainda, relação entre início precoce da distimia e comorbidades como TDM, transtorno do pânico e fobia social, além de uma maior duração da doença. (JURUENA; SPANEMBERG, 2004, p.305).

Outra patologia que acompanha sintomas depressivos é o Transtorno Bipolar, que pode ser classificado do tipo I e tipo II. No transtorno bipolar classificado como tipo I, o sujeito vivencia um ou mais episódios maníacos com a possibilidade, embora não a necessidade, de experimentar episódios depressivos maiores. Em compensação, um diagnóstico do transtorno bipolar tipo II significa que o sujeito teve um ou mais episódios depressivos maiores e pelo menos um que é classificado de episódio hipomaníaco. A pessoa no estado maníaco apresenta euforia exagerada, pensamento acelerado podendo evoluir para fuga de ideias, diminuição do sono, agitação psicomotora e aumento da libido. Segundo Moreno et.al (2005, p. 40). “O discurso é caracterizado por prolixidade, pressão para falar e tangencialidade. As ideias costumam ser de grandeza, podendo ser delirantes". A hipomania é um estado de mudança de humor com duração mínima de quatro dias consecutivos, não podendo ser considerada um tipo mais "leve" do transtorno bipolar I, uma vez que os prejuízos desse transtorno são refletidos na vida social do indivíduo. Logo, no DSM-V, o critério diagnóstico " $E$ " relata que “O episódio não é suficientemente grave a ponto de causar prejuízo acentuado no funcionamento social ou profissional ou para necessitar de hospitalização. Existindo características psicóticas, por definição, o episódio é maníaco". (AMERICAN PSYCHIATRIC ASSOCIATION DSM-V , 2014, p. 125). Sendo assim, não se pode desmerecer a gravidade do transtorno bipolar tipo II perante as diferenças dos sintomas por eles apresentados.

Há outras abordagens que buscam entender como a depressão é adquirida, como a perspectiva sociocultural que diz que os indivíduos desenvolvem a doença em resposta às circunstâncias de fatores estressantes da vida. Essas circunstâncias envolvem eventos específicos, como pessoas que sofreram algum tipo de violência sexual; estresse crônico; níveis de pobreza extrema e ser pai/mãe solteiro sem condições de poder cuidar do filho; ou estresse episódico, como luto ou perda do emprego. As mulheres têm mais probabilidade à exposição desses estressores e, consequentemente, têm mais riscos de desenvolver a depressão. (HAMMEN, 2005 apud HALGIN; WHITBOURNE, 2015). A invisibilidade e a desqualificação dos sintomas depressivos trazem 
ao paciente a vergonha de falar dos seus sentimentos a outras pessoas que, pela ignorância, classificam os sintomas como "frescuras", "falta de trabalho" etc. Para que pensamentos como esses não surjam, é dever dos profissionais da saúde estimular discussões nas mídias sociais e criar projetos que propaguem informações sobre a depressão.

\section{Aspectos neurobiológicos que interligam estresse e depressão}

Alterações psicológicas e comportamentais estão relacionadas com alterações fisiológicas, o que nos mostra que de fato vários aspectos dos seres humanos estão interligados e que é um erro dissociá-los, ou seja, ao se pensar em uma patologia, não se deve considerar apenas um único viés. No estresse, por exemplo, há participação do sistema nervoso, imune e endócrino, que, em consequência de glicocorticoides e imunossupressores, muitas doenças podem se formar devido a problemas de adaptação e à grande diversidade de estímulos, que acabam afetando o sistema imunológico. (PAGLIARONE; SFORCIN, 2009).

A constante interação com eventos e fatores estressantes, possui impacto no desdobramento de transtornos depressivos. O que de fato ocorre ainda é pouco conhecido, porém, pesquisas buscam fundamento em mudanças no hipocampo, já que o estresse pode alterá-lo com remodelação dendrítica e inibição de neurogênese. Drogas antidepressivas atuam impedindo esse efeito. (GUIMARÃES; JOCA; PADOVAN, 2003).

Eventos bioquímicos relacionados a neurotransmissão monoaminérgica podem estar relacionados a depressão, já que a redução de monoaminas como a serotonina e noradrenalina ocorre em regiões do cérebro afetado pela depressão. (CALIXTO; PAULINO; PREZOTTO, 2009).

No campo da psiconeuroimunologia, os estudos mostram que há ativação do eixo hipotálamo-pituitário-adrenal (HPA) e sistema nervoso autônomo (SNA) frente a um estímulo estressor, que em desequilíbrio pode provocar mudanças na resposta imune, fato que consequentemente poderá acarretar em patologias como infecções, câncer, doenças inflamatórias crônicas e a depressão. Frente a isso os estudos se voltaram para os chamados hormônios do estresse. (PAGLIARONE; SFORCIN, 2009).

A complexidade surge ao se verificar que a variação do efeito do estresse no organismo, depende da sua intensidade e duração, porém mesmo assim, é possível constatar que os hormônios se alteram frente a condição de estresse. Há aumento da secreção de catecolaminas (epinefrina e norepinefrina) pelo sistema nervoso autônomo; diminui a liberação do hormônio que libera gonadotrofinas $(\mathrm{GnRH})$ do hipotálamo e das gonadotrofinas da pituitária; liberação do hormônio que libera na circulação corticotropina (CRH), e, então, após alguns segundos, ocorre o aumento da secreção do hormônio 
adrenocorticotrófico $(\mathrm{ACTH})$ pela pituitária; aumento de prolactina, hormônio do crescimento $(\mathrm{GH})$ e glucagon. Já em caso de hemorragia, a arginina vasopressina (AVP) da pituitária e de renina do fígado ocorrem em grande escala. E, de forma, mais tardia aumentam os glicorticoides e diminuem os hormônios gonadais. (PAGLIARONE; SFORCIN, 2009).

As patologias surgem frente ao desequilíbrio do sistema neuroendócrino, tanto em níveis acima quanto abaixo do normal, que se reflete no desempenho e atividade do sistema imune. As citocinas, glicocorticoides e catecolaminas liberados durante o estresse são considerados cruciais no processo de desequilíbrio imune, já que, em altas concentrações inibem a resposta do Th1, causando depressão, doenças autoimunes e câncer. E quando estão em baixa concentração produzem citocinas Th2 que levam às doenças alérgicas e infeciosas. (PAGLIARONE; SFORCIN, 2009).

O estresse é um relevante fator ambiental que propicia o indivíduo à depressão; por muitas vezes, a depressão ocorre em pessoas que passaram por situações estressantes previamente, sobretudo as de origem psicossocial. Algumas evidências propõe a ação do hipocampo, já que o estresse pode gerar modificação plástica como a remodelação dendrítica e inibição de neurogênese na região hipocampal. Quando o estresse é demasiado e constante, ocorre um declínio dos receptores serotoninérgico no hipocampo, em relação a quantidade e atividade. Além disso, o estresse libera glicocorticoides de forma excessiva, que causa neurotoxidade e consequentemente perda neural, o que faria com que a frequência de episódios depressivos se tornasse recorrente. Há relatos de que a atrofia do hipocampo em pessoas deprimidas possuem relação com tempo em que convivem com a doença, e não com a idade das pessoas. A alteração da memória em pessoas deprimidas, teria relação com instabilidade do eixo hipotálamo-hipófise-adrenal, resultando impacto adverso causados por hormônios do estresse sobre o hipocampo, e a ativação insistente desse eixo pode ampliar a vulnerabilidade orgânica para as mais variadas patologias mentais, como a depressão. (CALIXTO; PAULINO; PREZOTTO, 2009).

\section{Discussão}

Movidas pela curiosidade científica, validamos algumas perguntas sobre as definições de estresse e depressão; quais são as causas do estresse na vida contemporânea; principais sinais e sintomas do estresse e depressão; formas de prevenção ou acompanhamento do estresse; relação do estresse com doenças mentais ou doenças psicossomáticas; estresse crônico; e se podemos relacionar que casos de estresse e depressão aumentam com os anos. E então, analisamos entrevistas selecionadas pertinentes ao tema em sites confiáveis e profissionais renomados, para acharmos as devidas relações entre nossas perguntas validadas e respostas dos profissionais. 
A primeira entrevista analisada foi publicada pelo Tribunal Regional do Trabalho da $4^{\mathrm{a}}$ região (TRT4), concedida pela psicóloga Ana Maria Rossi que preside a International Stress Management Association no Brasil (Isma-BR), doutora em psicologia clínica e comunicação verbal, especialista em estresse e biofeedback na Florida State University e na Menninger Foundation nos EUA, e precursora das técnicas de autocontrole e biofeedback no Brasil. Durante a entrevista, conceitua o estresse como algo positivo (compras de um bem, férias) ou negativo (conflitos, doenças, demissões, separações) que requer a adaptação da pessoa, e que o mesmo evento pode ser estressor para um e para outro não; porém, as reações fisiológicas do estresse positivo e negativo são as mesmas, já que o organismo só expressa o estresse, não diferenciando as situações. No trabalho, as principais situações estressoras são a grande simultaneidade de tarefas, o tempo para realizá-las, falta de reconhecimento e relações interpessoais entre os colaboradores. Faz uma crítica à sociedade ao dizer que as pessoas não reparam no próprio corpo, ou seja, o aparecimento de um sintoma ou seu agravamento, tanto em frequência, duração, ou intensidade, já seria um sinal de desequilíbrio que requer tratamento; porém, muita das vezes as pessoas tomam remédios para encobrir tais sintomas ao invés de fato tratá-los. (TRIBUNAL REGIONAL DO TRABALHO DA $4^{\mathrm{a}}$ REGIÃO, 2013).

A segunda entrevista analisada foi retirada do site do médico Drauzio Varella, concedida pela Alexandrina Meleiro, que é médica psiquiatra e trabalha no Instituto de Psiquiatria do Hospital das Clínicas da Universidade de São Paulo. Durante a entrevista ela alerta para o acúmulo dos pequenos problemas do dia a dia; o estresse é uma defesa natural, porém a repetição dele gera consequências danosas no organismo, afetando o comportamento além do sistema imunológico, endócrino e nervoso, levando a infarto, aumento da pressão arterial, alterações na pele, dores musculares, falta de energia, e irritabilidade, por exemplo. Geralmente, a própria pessoa não nota com clareza o que está acontecendo com ela e é alguém de fora que a alerta. Não é coerente esperar uma doença se instalar para tomar uma atitude, se o fator que gera a doença é emocional, também deve ser valorizado. Para prevenir o estresse primeiramente deve se verificar a possibilidade de se afastar do que o causa, e se não for possível, deve pensar em soluções como horas de sono suficientes, lazer e atividade física, além de ajuda profissional. (VARELLA, 2016).

A terceira entrevista analisada foi retirada do site Época Negócios, concedida pelo Armando Ribeiro, psicólogo, especialista em gestão do estresse, que coordena o Programa de Avaliação do Estresse do Centro Avançado em Saúde da Beneficência Portuguesa de São Paulo, e realiza consultoria. O quadro do estresse pode ir evoluindo até chegar na fase de Exaustão que é quando as doenças incluindo a depressão já estão instaladas, e que geralmente são de 
difícil tratamento já que os médicos olham diretamente para a doença e não para o que pode estar causando a doença, não contextualizam as queixas dos pacientes. Observa-se uma piora no aumento do estresse com o passar dos anos. As exigências do mundo moderno fazem com que as pessoas sejam mais cobradas, como por exemplo, na rapidez de respostas no trabalho, exigindo uma grande carga mental e física, as diversas opções excessivas oferecidas pelo mundo é uma fonte de estresse. A falta de foco estressa ainda mais e reforça que as pessoas deveriam lidar com um problema de cada vez, para não perder o foco. (BOURROUL, 2015).

A quarta entrevista analisada foi retirada do site do médico Drauzio Varella, concedida pelo Ricardo Moreno, que é médico psiquiatra do Instituto de Pesquisa da Universidade de São Paulo. A tristeza é um fenômeno normal e de curto prazo, já a depressão é patológica e afeta a pessoa por mais tempo, provoca desanimo, falta de interesse e prazer em atividades que anteriormente apresentava interesse, queda do desempenho, mudança de atitudes, alterações do sono e apetite, pensamentos negativos, e prejudica o aspecto psicológico e social. Ocorrem alterações bioquímicas no cérebro que se reflete em mudanças psicológicas e comportamentais. Nas mulheres a depressão é mais frequente até mesmo pelos vários processos hormonais que ocorrem durante a vida (ciclos menstruais, gravidez, parto e menopausa), tornando a mulher mais vulnerável. Além disso existe a predisposição genética que fará com que fatores estressores, sejam eles psicológicos ou físicos, se tornem desencadeadores da depressão, devem ser considerados fatores genéticos e ambientais. (VARELLA, 2017).

\section{Considerações finais}

O conceito de estresse passou por grande evolução desde a proposição feita por Selye, em 1936, considerando atualmente as diferenças individuas e a subjetividade; levando em conta o significado que a pessoa dá a um fato, o que fará com que o mesmo evento possa ser distinto a cada um, e as respostas adaptativas, que farão com que as respostas aos mais variados eventos estressores possam ser minimizados ou maximizados. Portanto, existe uma relação entre o que antecede, processos e resultado, ou seja, estímulo, organismo e resposta. Devido a toda essa percepção particular que cada pessoa dará diante de experiências de vida, fica evidente de que nem todas as experiências serão estressoras, e nem todos os estressores produzirão estresse da mesma forma nas pessoas; portanto, a perspectiva cognitiva se mostrou mais completa por considerar todos esses fatores, porém cada perspectiva teve sua importante contribuição. A perspectiva baseada na resposta, por exemplo, impulsionou os primeiros estudos sobre o estresse, além da descrição de como o organismo é afetado em seus níveis; já no caso da perspectiva baseada no estímulo, foi 
de suma importância o mapeamento de estressores e análise de tais adversidades sobre o organismo, contribuindo para estudos do estresse no âmbito da psicologia, até se chegar à perspectiva cognitiva, que prioriza as significações e relações entre a pessoa e o mundo; logo, as três perspectivas, de certa forma, se complementam.

Analisando os dados da pesquisa sobre o estresse realizada no Brasil, foi possível constatar que uma grande parte dos entrevistados se auto percebem como passando por estresse em níveis elevados, e consideram que o nível está acima do normal. Parte dos participantes percebem que o estresse tem aumentado com os anos, e que acreditam saber lidar em parte. Alguns dados como o nível do estresse e a evolução ao longo dos anos, é maior em brasileiros do que em americanos. Entre as patologias psicológicas relacionadas ao estresse, se destacaram ansiedade, depressão e pânico; já as de origem psicossomáticas se destacaram gastrite e doenças respiratórias. Ainda de acordo com a pesquisa, relacionamentos interpessoais, dificuldades financeiras e trabalho ocupam o topo do que mais fazem surgir estresse, e as pessoas buscam as mais variadas alternativas a fim de contornar o estresse, sendo que menos da metade dos entrevistados alegaram buscar ajuda profissional de um psicólogo.

Quanto a depressão, a qual tem sido crescente seu diagnóstico, foi visto durante esse artigo que até 2020 essa patologia será uma das mais incapacitantes, e que no mundo 322 milhões de pessoas já sofrem com esse mal, estando o Brasil, no primeiro lugar do ranking entre os países da América Latina com mais deprimidos. Buscando entender como a depressão é adquirida, por meio da perspectiva sociocultural, a patologia surge frente a fatores estressantes da vida, relacionando então o estresse à depressão. E pelo viés psiquiátrico, já que a depressão é um desequilíbrio das funções químicas cerebrais, principalmente a desarmonia dos neurotransmissores, buscou apresentar informações se as alterações cerebrais sofridas pelo estresse possuem relação com a depressão, e então pôde se constatar que, frente a estresse demasiado, ocorre declínio dos receptores serotoninérgicos no hipocampo, e liberação de glicocorticoides excessivamente, que causam a neurotoxidade e perda neural, causando a depressão; além disso, as citocinas e catecolaminas liberadas durante o estresse causam o desequilíbrio imune, levando à depressão; e ainda, o eixo hipotálamopituitário-adrenal (HPA) e sistema nervoso autônomo (SNA) frente a um estímulo estressor, gera desequilíbrio, provocando mudanças na resposta imune, o que poderá levar à depressão e outras doenças.

Portanto, nesse estudo, fica evidente que o estresse e a depressão estão abrangendo cada vez mais pessoas ao longo dos anos, e alterações psicológicas possuem relação com alterações fisiológicas. Por isso, ao se pensar no ser humano, é imprescindível ter um olhar amplo, para poder relacionar os mais variados aspectos. É claro que o nível de exposição aos estressores variará o grau das alterações 
fisiológicas e o grau ou tipo de doenças; porém também é determinante o significado que a pessoa dá a um evento, como ela lida com isso, e sua capacidade adaptativa, visto que a forma que a pessoa percebe e como isso impacta na sua vida, é o princípio para as alterações que levam à doença. Conclui-se que o problema e objetivo foram respondidos ao ponto que se encontrou uma relação entre o estresse e depressão.

\section{Referências}

AMERICAN PSYCHIATRIC ASSOCIATION. DSM-5: manual diagnóstico e estatístico de transtornos mentais. Transtorno Bipolar e transtornos relacionados. 5. ed. Porto Alegre: Artmed, 2014. p. 123-155.

AZEVEDO, Fabio Giorgio Santos; MAGALHÃES, Marilene Moreira da Silva. A depressão e a contemporaneidade: notas sobre o sintoma social. Revista Psicologia, Diversidade e Saúde. Bahia. v.5, n.2, p. 215226. Disponível em: <https://www5.bahiana.edu.br/index.php/ psico

logia/article/view/1046/772>. Acesso em: 14 de ago. 2017.

BEM ESTAR. Depressão cresce no mundo, segundo oms; brasil tem maior prevalência da américa latina. G1. Rio de Janeiro, 23 fev. 2017. Disponível em: <http://g1.globo.com/bem

estar/noticia/depressão-cresce-no-mundo-segundo-oms-brasil-temmaior-prevalencia-da-amer

ica-latina.ghtml>. Acesso em: 14 de ago. 2017.

BOURROUL, Marcela. A felicidade dentro da empresa é lucro. Época Negócios. 2015. Disponível em<http://epocanegocios.globo.com/ Informacao/Visao/noticia/2015/01/felicidade-dentro-da-empresa-elucro.html>. Acesso em: 22 out. 2017.

CALIXTO, Rosilene Farias; PAULINO, Célia Aparecida; PREZOTTO, Andrea Oriani. Associação entre estresse, depressão e tontura: uma breve revisão. Rev. Equilíbrio Corporal e Saúde, São Paulo, v.1, p.3345, 2009. Disponível em: <http://www.pgsskroton.com.br/ seer/ index.php/reces/article/view/180/167>. Acesso em: 12 ago. 2017.

CHOR, Dóra; FAERSTEIN, Eduardo; LOPES, Claudia S. Eventos de vida produtores de estresse e transtornos mentais comuns: resultados do Estudo Pró-Saúde. Cad. Saúde Pública, Rio de Janeiro, v. 19, n. 6, p. 1713-1720, dez. 2003. Disponível em: <http:/ / www.scielo.br

/ scielo.php?script=sci_arttext\&pid=S0102311X2003000600015\&lng=e n\&nrm=iso>. Acesso em: 17 abr. 2017.

CONFERENCIA INTERNACIONAL DE PROMOCIÓN DE LA SALUD, 4, 1997. Indonesia. Promoción de la salud: glosario. Ginebra: 
|A evolução do estresse e a fase de quase-exaustão como fator desencadeador da depressão

Organización Mundial de la Salud, 1998. Disponível em: <http:// www.who.int/iris/handle/10665/67246>. Acesso em: 31 abr. 2017.

DANIEL, Cristiane; SOUZA, Mériti de. Modos de subjetivar e de configurar o sofrimento: depressão e modernidade. Psicol. rev. (Belo Horizonte), Belo Horizonte, v. 12, n. 20, p. 117-130, dez 2006. Disponível em: <http:/ / pepsic.bvsalud.org/scielo.php?script=sci_arttext\&pid $=\$ 167711682006000200002 \& \operatorname{lng}=$ pt\&nrm=iso $>$. Acesso em: 17 abr. 2017.

DANTAS, Jurema Barros; MOURA, Michelle Thieme de Carvalho. Depressão: mal da humanidade? Possíveis relações entre depressão, saber "psi" e modos contemporâneos de subjetivação. Mnemosine, Rio de Janeiro, v.7, n.1, p.79-97, ago. 2013. Disponível em: <http://www. mnemosine.com.br/ojs/index.php/mnemosine/article/view/215/ pdf_200>. Acesso em: 17 abr. 2017.

ESTEVES, Fernanda Cavalcante; GALVAN, Alda Luiza. Depressão numa contextualização contemporânea. Aletheia, Canoas, n. 24, p. 127-135, dez. 2006. Disponível em: <http:/ / pepsic.bvsalud.org/scielo. php?script=sci_arttext\&pid=S141303942006000300012\&lng=pt\&nrm= is>. Acesso em: 17 abr. 2017.

EXTRA ONLINE. Brasil é o país mais deprimido da américa latina, aponta oms. EXTRA. Rio de Janeiro, 23 fev. 2017. Disponível em: $<$ https://extra.globo.com/noticias/saude-e-ciencia/

brasil-o-pais-mais-deprimido-da-america-latina-apontaoms-20969026.html>. Acesso em: 14 de ago. 2017.

FARO, André; PEREIRA, Marcos Emanoel. Estresse: Revisão Narrativa da Evolução Conceitual, Perspectivas Teóricas e Metodológicas. Psic., Saúde \& Doenças, Lisboa, v. 14, n. 1, p. 78-100, mar. 2013. Disponível em: <http://www.scielo.mec.pt/scielo.php?script=sci arttext\&pid $=S 164500862013000100006 \& \operatorname{lng}=$ pt\&nrm=iso $>$. Acesso em: 17 abr. 2017.

GUIMARÃES, Francisco Silveira; JOCA, Sâmia Regiane L; PADOVAN, Cláudia Maria. Estresse, depressão e hipocampo. Rev. Bras. Psiquiatr., São Paulo, v. 25, supl. 2, p. 46-51, dec. 2003. Disponível em: http://www.scielo.br/scielo.php?script=sci_arttext\&pid=S1516$44462003000600011 \& \operatorname{lng}=\mathrm{en} \& n r m=\mathrm{iso}>$. Acesso em 12 ago. 2017.

HALGIN, Richard P.; WHITBOURNE, Susan Krass: Psicopatologia: Perspectivas clinícas dos transtornos psicológicos. Transtornos Depressivos. 7. ed. Porto Alegre: artmed, 2015. p. 164-182. 
JURUENA, Mario Francisco; SPANEMBERG, Lucas. Distimia: características históricas e nosológicas e sua relação com o transtorno depressivo maior. Revista de Psiquiatria do Rio Grande do Sul. v.26, n.3, p. 300-311>. Disponível em: <http://www.scielo.br/pdf/rprs/ v26n3/

v26n3a07.pdf > Acesso em: 01 de set. 2017.

LIPP, Marilda Emmanuel Novaes. O modelo quadrifásico do stress. Disponível em: <http://www.estresse.com.br/publicacoes/omodelo-quadrifasico-do-stress/>. Acesso em: 07 abr. 2017.

. Pesquisa: Stress Brasil. Disponível em: <http://www.estresse. com.br/pesquisa/stress-brasil/>. Acesso em: 21 set. 2017.

MORENO, Ricardo Alberto; MORENO, Doris Hupfeld; RATZKE, Roberto. Diagnóstico, tratamento e prevenção da mania e da hipomania no transtorno bipolar. Rev Psiq Clín, v. 32, n. Supl 1, p. 39-48, 2005. Disponivel em: <http://psiquiatriabh.com.br/wp/wpcontent/uplo ads/2015/01/Tratamento-psiquiatrico-da-mania-e-hipomania.pdf $>$. Acesso em: 19 de set. 2017.

OLIVEIRA, Edson Alves de. Delimitando o conceito de stress. Ensaios e Ciência, São Paulo 1, nov. 2006. Disponível em: <http://www.sare. anhanguera.com/index.php/rensc/article/view/

327>. Acesso em: 17 abr. 2017.

PAGLIARONE, Ana Carolina; SFORCIN, José Maurício. Estresse: revisão sobre seus efeitos no sistema imunológico. Departamento de Microbiologia e Imunologia, Instituto de Biociências, UNESP, Londrina, v. 11, n. 1, p. 57-90, jan./jun. 2009. Disponível em: <http:// www.uel.br/ccb/patologia/portal/pages/arquivos/Biosaude $\% 20$ v\%2011\%202009/BS_v11_n1_DF_57.pdf>. Acesso em: 12 ago. 2017.

PEREIRA, Érico Felden; SANTOS, Anderlei dos; TEIXEIRA, Clarissa Stefani. Qualidade de vida: abordagens, conceitos e avaliação. Rev. bras. educ. fís. esporte, São Paulo, v. 26, n. 2, p. 241-250, jun. 2012. Disponível em: <http://www.scielo.br/scielo.php?script=sci_arttext\&pid S180755092012000200007\&lng=en\&nrm=iso>. Acesso em: 17 abr. 2017.

TRIBUNAL REGIONAL DO TRABALHO DA $4^{a}$ REGIÃO. Entrevista: psicóloga Ana Maria Rossi fala sobreestressenotrabalho.Jusbrasil.2013. Disponível em: < https://trt-4.jusbrasil.com.br/noticias/100555556/ entrevista-psicologa-ana-maria-rossi-fala-sobre-estresse-no-trabalho>. Acesso em: 22 out. 2017.

VARELLA, Drauzio. Entrevista depressão: doença que precisa de 
|A evolução do estresse e a fase de quase-exaustão como fator desencadeador da depressão

tratamento. 2017. Disponível em: < https://drauziovarella.com.br/ entrevistas-2/depressao-doenca-que-precidadetratamento/>. Acesso em: 22 out. 2017.

- Entrevista Estresse. 2016. Disponível em: < https:// drauziovarella.

com.br/entrevistas-2/estresse/>. Acesso em: 22 out. 2017. 